\title{
Estratégias na suplementação de vacas leiteiras no semi-árido do Brasil
}

\author{
Marcelo de Andrade Ferreira ${ }^{1}$, Fabiana Maria da Silva ${ }^{2}$, Safira Valença Bispo ${ }^{2}$, Marcílio de \\ Azevedo 1
}

\author{
${ }^{1}$ Dept. Zootecnia - Universidade Federal Rural de Pernambuco. \\ 2 PDIZ/UFRPE.
}

RESUMO - A região semi-árida do Brasil prolonga-se por uma área de $928 \mathrm{~km}^{2}$ abrangendo uma parte do norte dos estados de Minas Gerais e Espírito Santo, os sertões da Bahia, Sergipe, Alagoas, Pernambuco, Paraíba, Rio Grande do Norte, Ceará e Piauí e mais 45 municípios do sudeste do Maranhão. A população é predominantemente rural e a ocupação principal de sua força de trabalho é a agropecuária. A pecuária leiteira aparece como uma das poucas opções nas regiões semi-áridas, principalmente no nordeste do Brasil, onde a alimentação dos rebanhos fundamenta-se na utilização de forrageiras cultivadas e no uso da vegetação nativa, predominantemente a caatinga, aspecto que imprime características estacionais à produção nesta região. A escassez e irregularidade acentuada na distribuição de chuvas, tanto no tempo quanto no espaço, com a ocorrência de longos períodos de estiagem, praticamente, determina a obrigatoriedade de suplementação de vacas leiteiras nos sistemas de produções em regiões semi-áridas do Brasil.Desta forma, a suplementação tem se baseado na utilização de recursos forrageiros adaptados à seca, co- produtos e resíduos da agroindústria local e em alimentos concentrados. Algumas alternativas têm sido utilizadas pelos produtores na tentativa de reduzir custos sem perder produtividade nos períodos de estiagem. Para superar as adversidades alguns sistemas de produção têm sido propostos como o CBL (Caatinga-buffel-leucena) e o Sistema Glória. Além desses sistemas mencionados anteriormente, merecem destaque a utilização de co-produtos agroindustriais, restos de cultura, além de forrageiras nativas e adaptadas. Neste aspecto, a palma forrageira (Opuntia fícus indica-Mill) merece atenção especial pela sua grande adaptação, valor nutritivo e produtividade.

Palavras-chave: concentrado, sistema de produção, sustentabilidade, volumoso

\section{Strategies for the supplementation of dairy cows in the Brazilian semi-arid}

\begin{abstract}
The Brazilian semi-arid region has $928 \mathrm{~km}^{2}$ ranging from the northern portion of Minas Gerais and Espirito Santo States, the semi-arid lands of Bahia, Sergipe, Alagoas, Pernambuco, Paraíba, Rio Grande do Norte, Ceará, and Piauí States, and 45 counties from southeastern Maranhão State. Population is mainly concentrated in rural areas and the major occupation is agriculture and livestock production. Dairy production is one of the few options in these areas, mainly in northeast Brazil, where the feeding systems are based on cultivated forage crops and use of native vegetation, predominately the "Caatinga". These aspects give seasonal characteristics for the production on this region. Inadequate amount and distribution of rainfall in this region presenting strong spatial and seasonal variability and prolonged dry periods practically determines the need for supplementation feeding for dairy cows for production systems located in the semi-arid region. Thus, supplementation has been based on the use of forage resources adapted to the drought, by-products, residues from local agro-industry, and on concentrate feeding. Farmers are also using different options trying to reduce costs without losing productivity during the dry periods. Production systems such as "CBL" (Caatinga-Buffel Grass-Leucaena) and "Gloria System" have been proposed aiming to alleviate the adversities. In addition to these systems, the utilization of agro industrial by-products, crop residues, and native forage resources are important options. In this aspect, the forage cactus (Opuntia ficus-indica Mill.) deserves special attention for its great adaptation, nutritive value, and productivity in the region.
\end{abstract}

Key Words: concentrate, production systems, roughage, sustainability

\section{Introdução}

A região semi-árida do Brasil prolonga-se por uma área de $928 \mathrm{~km}^{2}$ abrangendo uma parte do norte dos estados de Minas Gerais e Espírito Santo, os sertões da Bahia, Sergipe, Alagoas, Pernambuco, Paraíba, Rio Grande do Norte, Ceará e Piauí e mais 45 municípios do sudeste do Maranhão. Os solos são rasos e assentados sobre o substrato cristalino, cobertos predominantemente pela vegetação caducifoliar das caatingas, típica da região. O tipo climático é Bsh, segundo a classificação de Köppen, caracterizando-se por temperaturas elevadas, baixa umidade do ar, alta insolação 
e elevadas taxas de evaporação, mas especialmente pela escassez e irregularidade acentuada na distribuição de chuvas, tanto no tempo quanto no espaço, com a ocorrência de longos períodos de estiagem. A estação chuvosa é curta e mais concentrada nos meses de verão. A precipitação em geral, situa-se entre 250 e $600 \mathrm{~mm} / \mathrm{ano}$, podendo atingir até $800 \mathrm{~mm} /$ ano. No Raso da Catarina, entre Bahia e Pernambuco os valores são inferiores a $500 \mathrm{~mm}$ anuais e a menor precipitação registrada no Brasil foi de $278 \mathrm{~mm} /$ ano em Cabaceiras, interior da Paraíba. O semi-árido apresenta temperaturas elevadas (média de $27^{\circ} \mathrm{C}$ ), com extremos, como Sobral-CE, com $28,9^{\circ} \mathrm{C}$, em dezembro. As altas temperaturas com pequena variação interanual, somadas à forte insolação, exercem forte efeito sobre a evapotranspiração, fazendo com que os reservatórios de água pouco profundos se esgotem rapidamente.

A população é predominantemente rural e a ocupação principal de sua força de trabalho é a agropecuária. É justamente da conjugação do meio ambiente adverso com a atividade econômica, basicamente dependente da natureza, que emerge a estrema vulnerabilidade desse sistema produtivo sujeito a virtuais colapsos, nas ocasiões climáticas desfavoráveis a produção.

A pecuária leiteira aparece como uma das poucas opções nas regiões semi-áridas, principalmente no nordeste do Brasil, onde a alimentação dos rebanhos fundamenta-se na utilização de forrageiras cultivadas e no uso da vegetação nativa, predominantemente a caatinga, aspecto que imprime características estacionais à produção nesta região. Desta forma, a suplementação tem se baseado na utilização de recursos forrageiros adaptados à seca, co-produtos e resíduos da agroindústria local e em alimentos concentrados. Algumas alternativas têm sido utilizadas pelos produtores na tentativa de reduzir custos sem perder produtividade nos períodos de estiagem.

A caatinga é rica em espécies forrageiras em seus três estratos, herbáceo, arbustivo e arbóreo. Estudos têm revelado que acima de $70 \%$ das espécies botânicas da caatinga participam significativamente da composição da dieta dos ruminantes domésticos. Em termos de grupos de espécies botânicas, as gramíneas e dicotiledôneas herbáceas perfazem acima de $80 \%$ da dieta dos ruminantes, durante o período chuvoso. Porém, à medida que a estação seca progride e com o aumento da disponibilidade de folhas secas de árvores e arbustos, estas espécies se tornam cada vez mais importantes na dieta.

Estrategicamente, as espécies lenhosas são fundamentais no contexto de produção e disponibilidade de forragem no semi-árido. Entre as diversas espécies, merecem ser destacadas: a maniçoba (Manihot pseudoglaziovii), o angico (Anadenanthera macrocarpa Benth), o pau ferro (Caesalpinia ferrea Mart. ex. Tul.), a catingueira (Caesalpinia pyramidalis Tul.), a catingueira rasteira (Caesalpinia microphylla Mart.), a favela (Cnidoscolus phyllacanthus (Muell.arg.)PaxetK.Hoffman), a canafistula (Senna espectabilis), o marizeiro (Geoffrae spinosa Jacq.) o mororó (Bauhinia sp.), o sabiá (Mimosa caesalpiniifolia Benth.), o rompe gibão (Pithecelobium avaremotemo Mart.) e o juazeiro (Zyzyphus joazeiroMart.), entre as espécies arbóreas; a jurema preta (Mimosa tenuiflora (Willd) Poiret), o engorda-magro (Desmoddium $s p$ ), a marmelada de cavalo (Desmosium $s p$ ), o feijão bravo (Phaseolus firmulus Mart.), a camaratuba (Cratylia mollis Mart. ex Benth) e o mata pasto (senna sp), entre as espécies arbustivas e semi-arbustivas. Destacam-se ainda as cactáceas forrageiras, facheiro (Pilosocereus pachycladus Ritter), mandacaru (Cereus jamacaru) e xiquexique (Drumond et al., 2004). Apesar da diversidade citada anteriormente, a produção média anual de fitomassa da vegetação nativa da caatinga é baixa, com variações provenientes de diferenças nos sítios ecológicos e flutuações climáticas. Do total de fitomassa produzida apenas cerca de $6 \%$ pode ser considerada como forragem se a exploração for com bovinos (Mesquita et al., 1988).

Segundo Moreira (2005), há muito se busca uma espécie forrageira capaz de suportar as longas estiagens que ocorrem no semi-árido e ainda assim ser produtiva. O autor concluiu que essa espécie já foi encontrada, o capim buffel (Cenchrus ciliaris L.) que atualmente se constitui na principal espécie forrageira cultivada neste ecossistema.

Para superar as adversidades anteriormente citadas alguns sistemas de produção têm sido propostos como o CBL (Caatinga-buffel-leucena) e o Sistema Glória. Além desses sistemas mencionados anteriormente, merecem destaque a utilização de co-produtos agroindustriais, restos de cultura, além de forrageiras nativas e adaptadas. Neste aspecto, a palma forrageira (Opuntia fícus indica- Mill) merece atenção especial pela sua grande adaptação, valor nutritivo e produtividade.

\section{Sistemas Glória e CBL}

Alguns sistemas de produção têm sido desenvolvidos por centros de pesquisas, como é o caso da EMBRAPA SEMI-ÁRIDO e praticados pelos produtores de leite das regiões áridas do Nordeste. Dentre eles destacam-se o Sistema Glória e o CBL.

O Sistema Glória (Sá, 2006) é um dos sistemas de produção de leite empregado no semi-árido nordestino, 
pois o mesmo engloba vários subsistemas que funcionam de forma integrada (agricultura/pecuária). No período chuvoso, o rebanho é mantido basicamente sob regime de pastejo alternado em áreas de gramíneas cultivadas (buffel, urocloa, pangolão e grama aridus), além das pastagens nativas de ciclo anual; com predominância do capim marmelada (Brachiaria plantagínea) e várias espécies de leguminosas herbáceas anuais, principalmente dos gêneros Phaseolus, Centrosema e Stylosanthes.

O que diferencia esse sistema de outros convencionais é o sistema de alimentação, fundamentando-se na otimização do uso de forragens de boa qualidade, produzindo a partir da infra-estrutura agrossilvopastoril mencionada, com uso moderado e estratégico de rações concentradas e consequente redução dos custos operacionais. Dentre os alimentos utilizados, mais uma vez destaca-se a palma forrageira, que inicialmente era utilizada em circunstâncias emergenciais, geralmente em longos períodos de seca. Todavia, em função de seu potencial energético, a palma tem sido utilizada quase todo ano nas dietas. A glirícidia é utilizada na confecção de feno e silagem, sendo também oferecida verde, no cocho. Entre outros usos, esta leguminosa forrageira arbórea, de crescimento rápido e alta resistência a seca, por ser facilmente propagada vegetativamente por estacas e, principalmente, por manter a folhagem verde em plena seca, é particularmente indicada para formação de cercas vivas forrageiras.

Assim sendo, pode-se considerá-lo como um sistema sustentável, de reduzido uso de insumos externos, para produção de leite a baixo custo, fundamentado em:

. Mão-de-obra familiar e tração animal;

- Infra-estrutura agrossilvopastoril adaptada à seca;

- Animais zootecnicamente compatíveis com o ambiente;

Prática de conservação de forragem e enriquecimento de restos de culturas;

- Cultivos consorciados e reciclagem de resíduos vegetais e animais.

Outro sistema utilizado nas regiões semi-áridas do nordeste é o CBL (caatinga-buffel-leucena) (Filho, 1999). Esse sistema foi desenvolvido por pesquisadores do Centro de Pesquisa Agropecuária do Trópico Semi-Árido (CPTSA). Em sua concepção básica, o sistema CBL apresenta cinco características fundamentais:

- Utiliza caatinga como um de seus componentes, por dois a quatro meses do ano;

- Utiliza pastos tolerantes à seca, em sistema rotacional, para complementar a alimentação volumosa do rebanho no restante do ano;
- Utiliza feno e silagem produzidos a partir de bancos de proteína/energia para suplementar a alimentação dos animais nos períodos mais críticos;

- Mantém uma reserva estratégica de espécies forrageiras de alta tolerância às secas mais severas para assegurar nestes períodos, um nível satisfatório de produtividade do rebanho e,

- Funciona como um subsistema capaz de se adequar e interagir com os demais componentes da unidade produtiva, dentro da diversidade agroecológica e sócioeconômica observada no semi-árido.

A caatinga é pastejada por dois a quatro meses do ano, em função do nível de pluviosidade ocorrido, período em que a mesma oferece o máximo em termos de quantidade e qualidade de forragem. A gramínea que mais tem se adaptado ao sistema é o capim buffel, por ser bastante tolerante à seca, sendo pastejado diretamente, em sistema rotacionado, nos oito a dez meses em que a caatinga oferece menor capacidade suporte. A espécie que melhor tem se comportado como banco de proteína é a leucena, a qual é cortada e transformada em feno ou silagem na primeira metade do período verde, para uso no período seco e, posteriormente, com a rebrota, pastejada diretamente (uma hora por dia).

A palma forrageira é utilizada também nesse sistema na forma de cultivo consorciado com área de reserva estratégica para assegurar uma produtividade satisfatória nos anos de seca mais intensa, quando a produção de leucena é fortemente afetada. Práticas de manejo reprodutivo e sanitário complementam o sistema.

Além de todos os benefícios citados anteriormente, o sistema incorpora uma série de práticas de manejo capazes de, aproveitando o forte poder de reabilitação natural da caatinga, reverter o seu processso de degradação. Entre estas práticas, destacam-se: taxa de lotação apropriada, pastejo estacional, pastejo em áreas suplementares e suplementação alimentar no período crítico.

Paulino et al. (2008), sugerem uma derivação estendida (ampliada) do sistema CBL, o CGS (Caatinga - Gramínea Suplementação), trazendo embutida a idéia de suplementação volumosa para incrementar a disponibilidade de matéria seca potencialmente digestível. A eleição de espécies forrageiras em ambientes sujeitos ao estresse hídrico deve considerar mecanismos morfofisiológicos que combinem se para evitar ou tolerar o déficit hídrico. Assim, para a região semi-árida podem ser recomendadas, além do capim búffel (Cenchus ciliares), outras gramíneas como o capim gramão (Cynodon dactylon var. aridus), o capim corrente (Uruchloa mosambicensis) e o capim andropogon (Andropogon gayanus var. bisquamulatus). 


\section{Palma forrageira}

A palma forrageira se apresenta como recurso alimentar de extrema importância. Adaptada às condições edafoclimáticas da região, tem sido freqüentemente utilizada na alimentação de bovinos leiteiros, notadamente nos períodos de estiagem prolongada. Uma comparação entre características agronômicas da palma e do milho é feita na Tabela 1. Nota-se claramente a superioridade da palma sobre o milho em quase todos os aspectos.

A palmaforrageira, independente do gênero, apresenta baixos teores de MS (11,69 $\pm 2,56 \%)$, PB (4,81 1,16\%), FDN $(26,795,07 \%)$ e FDA $(18,853,17 \%)$. Por outro lado, apresenta teores consideráveis de CHT $(81,125,9 \%)$, CNF $(58,55 \pm 8,13 \%)$ e matéria mineral $(12,044,7 \%)$. A palma forrageira é muito digestível, apresentando coeficientes de digestibilidade in vitro na matéria seca da ordem de 74,$4 ; 75,0$ e 77,40\% para as cultivares redonda, gigante e miúda, respectivamente.

A palma forrageira apresenta alta palatabilidade e grandes quantidades podem ser voluntariamente consumidas. No entanto, embora seja uma excelente fonte de CNF (importante fonte de energia para os ruminantes), a palma forrageira apresenta baixos teores de MS, FDN e o teor de PB é insuficiente para o adequado desempenho animal. Assim, no intuito de correção da FDN a palma forrageira foi associada com diferentes volumosos, em dietas para bovinos leiteiros (Tabela 2) e não foram observados, diarréia, perda de peso, alterações no consumo de matéria seca ou queda no teor de gordura no leite. Deve-se salientar sobre a composição que todos os estudos, os teores de FDN e CNF estiveram dentro do limite preconizado pelo NRC (2001), para manutenção das condições normais do rúmen.

Dentre as opções de forrageiras existentes, o sorgo e o girassol vem sendo utilizados na forma in natura ou conservada, por apresentarem boa capacidade produtiva e alto valor nutritivo. O sorgo tem sido uma opção vantajosa em regiões mais secas, sendo o girassol uma alternativa devido seu alto rendimento de silagem, com baixos riscos de fracassos em razão de sua tolerância a seca e ao calor (Oliveira, 2008).

Outro fato que imprime bastante preocupação entre os produtores de leite é o aumento no uso de concentrado para manter a produção de leite, em período de estiagem.

Tabela 1 - Aspectos agronômicos das culturas da palma e do milho

\begin{tabular}{lcc}
\hline Item & Palma & Milho \\
\hline Tipo de fotossíntese & MAC & C4 \\
Eficiência no uso da água (kg água/kg MS) & 100 & 300 \\
Resistência a seca & alta & baixa \\
Risco Agrícola & baixo & alto \\
Ciclo & perene & $90-120$ dias \\
Coincidência chuva/ciclo & total & limitada \\
Requerimento de mecanização do solo & baixo & alto \\
Requerimento de máquinas & baixo & alto \\
Requerimento de mão de obra & alto & baixo \\
Potencial de erosão do solo & baixo & alto \\
Necessidade de armazenamento & não & sim \\
Produtividade (kg MS/ha/ano) & $10-20$ & $0-10$ \\
R $/$ kg MS & $0,20-0,25$ & $? ? ?$ \\
\hline
\end{tabular}

Tabela 2 - Associação da palma forrageira com diferentes volumosos

\begin{tabular}{|c|c|c|c|c|c|c|c|}
\hline Volumoso & PL & Palma \% & Volumoso $\%$ & Concentrado $\%$ & FDN \% & $\mathrm{CNF} \%$ & Referência \\
\hline SS & 13,9 & 38,0 & 37,80 & 23,2 & 40,45 & 35,00 & Mattos et al. (2000) \\
\hline $\mathrm{BC}$ & 13,6 & 55,4 & 17,80 & 25,3 & 36,00 & 39,00 & \\
\hline SS & 29,5 & 29,00 & 28,00 & 43,00 & 34,00 & 41,50 & Melo et al. (2007) \\
\hline FCT & 17,6 & 49,81 & 25,35 & 22,31 & 34,60 & 42,39 & Silva et al. (2007a) \\
\hline FCE & 17,6 & 46,66 & 27,98 & 22,33 & 33,91 & 42,26 & \\
\hline $\mathrm{BC}$ & 16,2 & 50,05 & 24,07 & 22,34 & 36,38 & 41,47 & \\
\hline SS & 25,7 & 24,00 & 33,00 & 43,00 & 31,90 & 43,42 & Wanderley et al. (2002) \\
\hline SS & 10,71 & 58,81 & 34,63 & 3,29 & 40,39 & 36,33 & Wanderley (2008) \\
\hline SG & 11,8 & 62,65 & 33,30 & 0,7 & 35,48 & 37,50 & \\
\hline FG & 9,85 & 60,46 & 35,79 & 0,64 & 40,63 & 37,16 & \\
\hline SS & 11,55 & 53,00 & 32,00 & 15,00 & 35,40 & 40,17 & Silva (2008) \\
\hline
\end{tabular}

Produção de leite (PL); silagem de sorgo (SS); bagaço de cana (BC);feno de capim Tifton (FCT); feno de capim-elefante (FCE); silagem de girassol (SG); feno deguandu (FG). 
Entretanto o alto valor do grão de milho como produto alimentício para consumo humano, a necessidade do seu uso na composição de rações para não-ruminantes, a dificuldade de produção em regiões semi-áridas e a necessidade de importação, tornam o seu custo elevado. Assim, o alto teor de carboidratos não fibrosos da palma forrageira tem despertado o interesse para sua utilização em substituição a concentrados energéticos e também sua associação com fontes de NNP, notadamente a uréia.

Véras et al. (2002), substituíram até $75 \%$ de milho moído por farelo de palma forrageira em ensaio de digestibilidade com bovinos, e não verificaram alteração no teor de energia das dietas. Vale ressaltar que o consumo foi restrito a $2,5 \%$ do peso vivo dos animais. No entanto, Véras et al. (2005) ao substituírem totalmente o milho moído por farelo de palma forrageira em dietas de ovinos em crescimento, alimentados, à vontade, observaram queda linear no ganho de peso dos animais e no teor de NDT das dietas, sem alteração no consumo de matéria seca.

A substituição total do milho por palma forrageira in natura e parcial do farelo de soja por palma forrageira in natura mais uréia, foi estudada em dietas para vacas em lactação (Tabela 3). Fato interessante observado, nesses estudos, foi a pouca alteração na produção de leite quando o milho foi substituído por palma, ao contrário no comportamento observado na substituição do farelo de soja , onde maiores alterações nas produções de leite foram verificadas. De maneira geral. Observa-se redução na produção de leite quando há inclusão de uréia em dietas para vacas em lactação, independentemente do concentrado utilizado com uréia.

O mais importante a ser observado é que com a substituição do concentrado ou parte do mesmo pela palma forrageira, os custos com alimentação podem ser reduzidos com menor utilização de concentrado e a alteração na produção de leite pode ser compensada, tornando-se economicamente vantajoso.

Além das vacas, a alimentação de novilhas é preocupante, neste sentido foram realizados alguns trabalhos sobre a utilização da palma forrageira em associação com o bagaço de cana em dietas de bovinos leiteiros em crescimento (Tabela 4).

A alta concentração de carboidratos solúveis na palma possibilita a incorporação de fontes de NNP com o objetivo de elevar o teor de proteína. Além disso, a associação com o bagaço de cana que possui alto teor de FDN (de baixo valor nutricional) possibilita por outro lado, a melhoria do aproveitamento da dieta, uma vez que introduz no sistema fibra de alta efetividade, visando melhor "saúde" ruminal e utilização dos nutrientes da dieta. Considera-se ainda a importância do fornecimento de uma fonte suplementar de aminoácidos (proteína verdadeira) em associação ao trinômio Palma-Fibra-NNP.

Além da palma forrageira, outras cactáceas são importantes na alimentação dos rebanhos. Em determinadas regiões semi-áridas do Nordeste brasileiro, as cactáceas nativas, particularmente o xiquexique (Pilosocereus gounellei) e o mandacaru (Cereus jamacaru DC.), são utilizadas durante períodos de secas prolongadas como um dos principais suportes forrageiros dos ruminantes. Além de suprir parte da demanda nutricional dos animais, essas cactáceas podem também suprir parte das exigências de água dos mesmos, devido ao mecanismo morfofisiológico de economia de água que possuem. Ambas caracterizam-se por se desenvolver em áreas mais secas da região semi-árida nordestina, em solos rasos com baixa fertilidade. Contudo, segundo Lima (1998), essas cactáceas possuem limitações para o uso na alimentação animal, por possuírem grande quantidade de espinhos, além do crescimento lento (o que leva a uma baixa produtividade, quando comparado com a palma forrageira, por exemplo) e o alto custo com mão-de-obra com o corte da planta, queima dos espinhos e trituração do material forrageiro (Menezes et al., 2005; Silva et al., 2007b).

\section{Co-produtos e resíduos da agroindústria}

Com o lançamento do Programa Nacional de Produção e Uso de Biodiesel pelo Governo Federal, cria-se uma janela

Tabela 3 - Palma forrageira em substituição de alimentos concentrados em dietas para vacas em lactação

\begin{tabular}{cccccccccc}
\hline PLCG & Palma $\%$ & Volumoso $\%$ & Milho $\%$ & Farelo de soja $\%$ & Uréia $\%$ & FDN \% & CNF \% & CC kg & Referência \\
\hline 19.36 & 31,94 & 30,44 & 14,27 & 21,95 & 0,00 & 36,57 & 36,98 & 8,00 & Melo et al. (2003) \\
17.87 & 37,77 & 31,20 & 13,92 & 14,04 & 1,58 & 37,72 & 34,28 & 6,00 & \\
15.90 & 36,00 & 37,00 & 15,12 & 8,37 & 1,89 & 39,64 & 36,68 & 3,70 & Araújo et al. (2004) \\
14.83 & 50,00 & 37,00 & 0,00 & 9,03 & 1,69 & 39,80 & 33,28 & 1,30 & Oliveira et al. (2007) \\
19.85 & 0,00 & 67,42 & 16,39 & 14,19 & 0,00 & 57.51 & 15,06 & 7,10 & \\
19.31 & 51,00 & 27,85 & 0,00 & 19,15 & 0,00 & 43,13 & 30,02 & 3,50 & \\
13.66 & 45,00 & 30,00 & 9,30 & 14,00 & 0,20 & 40,00 & 34,70 & 4,40 & Bispo (Dados não publicados) \\
11.12 & 60,00 & 30,00 & 0,00 & 6,88 & 1,63 & 41,50 & 34,40 & 1,30 & \\
\hline
\end{tabular}

Produção de leite corrigida para $4 \%$ de gordura (PLCG); consumo de concentrado (CC). 
Tabela 4 - Palma forrageira em dietas para novilhas

\begin{tabular}{lcccccc}
\hline Raça & Palma $\%$ & Bagaço $\%$ & Uréia $\%$ & Suplemento (kg/dia) & GP $(\mathrm{kg} / \mathrm{dia})$ & Referência \\
\hline Holandês & 69,80 & 27,60 & 2,60 & Farelo de trigo (1) & 0,71 & Carvalho et al. (2005) \\
Holandês & 69,80 & 27,60 & 2,60 & Farelo de soja (1) & $1, .20$ & Pessoa et al. (2007) \\
Mestiças* & 64,00 & 30,00 & 4,00 & Farelo de trigo (1) & 0,60 & 0,72 \\
Mestiças* & 64,00 & 30,00 & 4,00 & Farelo de soja (1) & 0,84 & \\
Mestças* & 64,00 & 30,00 & 4,00 & Farelo de algodão (1) & 0,75 & \\
Mestiças* & 64,01 & 30,01 & 4,01 & Caroço de algodão (1) & 0,43 & \\
Mestiças* & 64,02 & 30,02 & 4,02 & Sem suplemento & \\
\hline
\end{tabular}

*5/8 Holandês-Gir.

de oportunidade para a produção de ruminantes, através da oferta potencial de co-produtos obtidos após a extração do óleo vegetal e após o processo de conversão do óleo em biodiesel. Desta forma, permite-se integrar as cadeias de produção de agroenergia e de pecuária, potencializando a geração de emprego e renda, minimizando os passivos ambientais. Neste sentido, estudos que permitem gerar informações sobre a melhor forma de utilização dos coprodutos da cadeia do biodiesel na alimentação de ruminantes fazem-se necessários, para garantir a sustentabilidade desta integração.

No Brasil algumas culturas têm sido utilizadas com mais freqüência para produção de biodiesel: mamona, a soja, palmáceas, girassol, amendoim, algodão e pinhão manso. No entanto a utilização desses co-produtos foi pouco estudada, principalmente no semi-árido.

A cultura da mamona (Ricinus communis L.) é uma das mais tradicionais no semi-árido Brasileiro (Pereira et al., 2008 a). A expectativa de crescimento da cultura da mamona como matéria prima para geração de biodisel no Brasil cria uma janela de oportunidade para a produção de ruminantes, em razão da potencial oferta de torta e farelo de mamona, principais co-produtos da cadeia produtiva da mamona.

A torta da mamona é o produto obtido após extração mecânica do óleo, sendo constituído de, aproximadamente, $13 \%$ de óleo (Costa et al., 2004); enquanto o farelo de mamona consiste no produto obtido após a extração com solventes, e que segundo a ANFAR - Associação Nacional dos Fabricantes de Rações, deve apresentar um teor de óleo menor que 1,5\% (Evangelista et al., 2004). A torta corresponde a $55 \%$ do peso da semente, o que permite um rendimento aproximado de 1,2 toneladas de torta para cada tonelada de óleo extraído (Azevedo e Lima, 2001). Em razão da maior eficiência industrial do processo de extração de óleo com solventes (Baliza et al, 2004), o farelo de mamona deverá ser o principal produto obtido após a extração do óleo.

O farelo de mamona apresenta-se como um alimento concentrado protéico, com teor médio de proteína bruta (PB) de 40,7\%, base da MS (Valadares Filho et al., 2002).
Beltrão (2003) em uma compilação de dados sobre a torta de mamona verificou que a mesma apresenta $41,2 \%$ de proteína bruta, $2,62 \%$ de extrato etéreo, $32,84 \%$ de fibra, $7,65 \%$ de matéria mineral e $7,91 \%$ de extrato não nitrogenado para a torta de mamona.Já a casca da mamona apresenta em termos nutricionais $87,1 \%$ de MS, $9,0 \%$ de $\mathrm{PB}, 4,6 \%$ de EE, e 67,0\% de FDN (Gomes, 2007).

Apesar do potencial de utilização dos co-produtos da mamona na alimentação de ruminantes como substituto de fontes tradicionais de proteína (farelo de soja e farelo de algodão), o que poderia agregar maior valor e renda a cadeia produtiva, este produto tem sido utilizado maciçamente como fertilizante orgânico. A presença de um composto tóxico - a ricina, de um alcalóide - a ricinina, e de complexos alergênicos - CB-1A, bem como a carência tecnológica que propicie a obtenção de um alimento seguro e com preços competitivos, em escala industrial, tem impedido a sua adoção (Severino, 2005). Portanto a utilização da torta e do farelo de mamona como alimento para animais é feita após sua destoxificação.

A glicerina, resíduo do biodiesel, quando purificada na indústria tem diversos destinos, entre os quais se destacam os usos em tabaco, alimentos, bebidas e cosméticos, no entanto estes processos de purificação tem elevado custo, gerando a busca por alternativas para seu uso na forma pura. Para cada $90 \mathrm{~m}^{3}$ de biodiesel produzido são gerados $10 \mathrm{~m}^{3}$ de glicerina. Com a obrigatoriedade da adição de biodiesel ao diesel de petróleo, espera-se um excedente anual de 150 mil ton de glicerina no ano de 2013, o que possivelmente levará a uma redução nos preços. Esse cenário indica a necessidade de viabilização comercial deste volume extra de glicerina, buscando outras aplicações, como por exemplo, seu uso em rações para animais como uma ótima fonte de energia (Menten et al., 2009).

Outra fonte de suplementação, abundante no Nordeste brasileiro, são os resíduos da agro-indústria frutífera. Com a expansão das áreas irrigadas, a produção de resíduos já representa uma fonte considerável de alimentos de boa qualidade nutricional (Tabela 5).No entanto, a variabilidade 
Tabela 5- Composição nutricional de alguns resíduos da agroindústria frutífera

\begin{tabular}{|c|c|c|c|c|c|c|c|}
\hline \multirow[t]{2}{*}{ Nutriente (\%MS) } & \multicolumn{7}{|c|}{ Co-produto } \\
\hline & Cajú & Maracujá & Melão & Urucum & Abacaxi & Acerola & Goiaba \\
\hline MS & 96,32 & 97,31 & 97,53 & 95,26 & 97,62 & 97,25 & 86,30 \\
\hline PB & 15,93 & 9,70 & 8,75 & 13,53 & 7,84 & 9,06 & 8,50 \\
\hline MM & 3,62 & 13,27 & 6,85 & 6,32 & 10,70 & 6,08 & 3,40 \\
\hline MO & 96,40 & 86,70 & 93,20 & 93,70 & 89,30 & 93,90 & 96,60 \\
\hline EE & 1,50 & 0,40 & 0,80 & 2,10 & 0,60 & 0,90 & 6,00 \\
\hline FDN & 64,40 & 63,40 & 73,00 & 45,10 & 60,30 & 70,60 & 73,50 \\
\hline FDA & 43,76 & 54,03 & 62,58 & 20,18 & 32,86 & 59,92 & 54,70 \\
\hline
\end{tabular}

Fonte: Pereira et al. (2008b).

da qualidade observada nestes co-produtos pode ser de grande magnitude, uma vez que se trata de material sem padrão de qualidade, sujeitos a adulteração e contaminação, além da disponibilidade inconstante ao logo do ano, prejudicando as projeções futuras de utilização e compra de alimentos e em certos períodos do ano os co-produtos extrapolam os preços de alimentos de alto valor nutritivo. Portanto, a utilização deste recurso deve ser acompanhada de avaliação criteriosa para se evitar problemas de ordem sanitária e econômica (Damasceno et al., 2002). Da mesma forma que os co-produtos do biodiesel estes resíduos também não foram suficientemente pesquisados em dietas de vacas leiteiras no semi-árido.

\section{Considerações finais}

A bovinocultura leiteira é de grande importância social e econômica para o semi-árido brasileiro, principalmente na região Nordeste, por ser menos vulnerável à seca, quando comparada com outras explorações agrícolas, e se constituir num dos principais fatores de fixação do homem no campo e de geração de emprego e renda.

A escassez e irregularidade acentuada na distribuição de chuvas, tanto no tempo quanto no espaço, com a ocorrência de longos períodos de estiagem, praticamente, determina a obrigatoriedade de suplementação de vacas leiteiras nos sistemas de produções em regiões semi-áridas do Brasil.

A palma forrageira se apresenta com um dos principais suplementos para vacas leiteiras no semi-árido

Os co-produtos e resíduos da agroindústria apresentam potencial para serem utilizados como suplementos para vacas leiteiras no semi-árido.

Apesar da grande importância da bovinocultura de leite para as regiões semi-áridas do Brasil, poucos trabalhos de pesquisa têm sido desenvolvidos para dar maior sustentabilidade aos sistemas de produção neste ecossistema.

\section{Literatura Citada}

ARAÚJO, P.R.B.; FERREIRA, M.A.; BRASIL, L.H.A. et al. Substituição do milho por palma forrageira em dietas completas para vacas em lactação. Revista Brasileira de Zootecnia, v.36, n.6, p.1850-1857, 2004.

AZEVEDO, D.M.P.; LIMA, E.F. O Agronegócio da mamona no Brasil. Brasília: Embrapa Informação Tecnológica, 2001. $350 \mathrm{p}$.

BALIZA, D.P.; CARDOSO, M.G.; VILELA, F.J. et al. Extração do óleo fixo de torta oriundo da prensagem industrial de sementes de Ricinus communis (Mamona). In: CONGRESSO BRASILEIRO DE MAMONA, 1., 2004, Campina Grande. Anais eletrônicos... Campina Grande, 2004. Disponível em: <http://ww.cnpa.embrapa.br.>Acesso em: 14/4/2009.

BELTRÃO, N.E.M. Torta de mamona (Ricinus communis L.): fertilizante e alimento. Rio de Janeiro: Embrapa - CNPA, 2003, 4p. (Comunicado Técnico, 171).

CARVALHO, M.C.; FERREIRA, M.A.; CAVALCANTI, C.V.A. et al. Associação do bagaço de cana-de-açúcar, palma forrageira e uréia com diferentes suplementos em dietas para novilhas da raça holandesa. Acta Scientiarum. Animal Sciences, v.27. n.2, p.247-252, 2005.

COSTA, F.X.; SEVERINO, L.S.; BELTRÃO, N.E.M. Composição química da torta de mamona. In: CONGRESSO BRASILEIRO DE MAMONA, 1., 2004, Campina Grande. Anais eletrônicos... Campina Grande, 2004. Disponível em: <http://ww.cnpa.embrapa.br.>Acesso em: 14/4/2009.

DAMASCENO, J.C.; SANTOS, G.T.; CÔRTEZ, C. et al. Aspectos da alimentação da vaca leiteira. In: SUL-LEITE "SIMPÓSIO SOBRE SUSTENT ABILIDADE DA PECUÁRIALEITEIRA NA REGIÃO SUL DO BRASIL", 2., 2002, Maringá. Anais... Maringá: Universidade Estadual de Maringá, 2002. p.166-188.

DRUMOND, M.A.; SANTANA, A.C.; ANTONIOLI, A. et al. Recomendações para o uso sustentável da biodiversidade no bioma da Caatinga. In: BIODIVERSIDADE DA CAATINGA: áreas e ações prioritárias para a conservação. Brasília: MMAUFPE, 2004. p.47-90.

EVANGELISTA, A.R.; ABREU, J.G.; PERON, A.J. et al. Avaliação da composição química de tortas de mamona e amendoim obtidas por diferentes métodos de extração de óleo. In: CONGRESSO BRASILEIRO DE MAMONA, 1., 2004, Campina Grande. Anais eletrônicos... Campina Grande, 2004. Disponível em: <http://ww.cnpa.embrapa.br.>Acesso em: 14/4/2009.

FILHO, C.G.; SOARES, J.G.G. Sistema CBL para produção de bovinos no semi-árido. Petrolina: Embrapa - CPSATA, 1999, 4p. (Comunicação Técnica, 2).

GOMES, F.H.T. Composição químico-bromatológica e degradação in situ de nutrientes de co-produtos da mamona e do pinhão manso da cadeia produtiva do biodiesel. 2007. 49f. Monografia - Universidade Federal do Ceará, Fortaleza, 2007. 
LIMA, G.F.C. Alternativas de seleção e manejo de volumosos forrageiros para a atividade leiteira no Nordeste. In: SIMPÓSIO O AGRONEGÓCIO DO LEITE NO NORDESTE: alternativas tecnológicas e perspectivas de mercado, 1998, Natal. Anais... Natal: EPARN/FIERN/SENAI, 1998. p.192.

MATTOS, L.M.E.; FERREIRA, M.A.; SANTOS, D.C. et al. Associação da palma forrageira (Opuntia ficus indica Mill) com diferentes fontes de fibra na alimentação de vacas $5 / 8$ HolandêsZebu em lactação. Revista Brasileira de Zootecnia, v.29, n.6, p.2128-2134, 2000.

MELO, A.A.S.; FERREIRA, M.A.; VÉRAS, A.S.C. et al. Substituição parcial do farelo de soja por uréia e palma forrageira (Opuntia fícus indica Mill) em dietas para vacas em lactação. I. Desempenho. Revista Brasileira de Zootecnia, v.32, n.3, p.727-736, 2003.

MELO, A.A.S.; FERREIRA, M.A.; VÉRAS, A.S.C. et al. Caroço de algodão em dietas à base de palma forrageira para vacas leiteiras: síntese de proteína microbiana1. Revista Brasileira de Zootecnia, v.36, p.912-920, 2007.

MENEZES,R. S.C.; SIMÕES, D.A.; SAMPAIO, E.V.S.B. A palma no nordeste do Brasil: conhecimento atual e novas perspectivas de uso. Recife: Ed. Universitária da UFPE, 2005. 258p.

MENTEN, J.F.M.; MIYADA, V.S.; BERENCHTEIN, B. Glicerol na alimentação animal. [2009] Disponível em: < http:// www.agrolink.com.br/downloads/glicerol_2009-03-13.pdf > Acesso em: 3/4/2009.

MESQUITA, R.C.M.; ARAÚJO FILHO, J.A.; DIAS, M.L. Manejo de pastagem nativa: uma opção para o semi-árido nordestino. In: SIMPÓSIO NORDESTINO DE ALIMENTAÇÃO DE RUMINANTES, 2., 1988, Natal. Anais... Natal: EMPARN, 1988. p.124-140.

MOREIRA, J.M. Produção de leite de vacas guzerá e girolando utilizando a caatinga, no período chuvoso e pasto de capim buffel diferido, no período seco, no sertão de Pernambuco. 2005. 91f. Tese (Doutorado em Zootecnia) Universidade Federal Rural de Pernambuco, Recife, 2005.

NATIONAL RESEARCH CONUNCIL - NRC. Nutrient requirements of dairy cattle. 7.ed.rev. Washignton, D.C.: National Academy Press, 2001.

OLIVEIRA, V.S.; FERREIRA, M.A.; GUIM, A. et al. Substituição total do milho e parcial do feno de capim-tifton por palma forrageira em dietas para vacas em lactação. Consumo e digestibilidade. Revista Brasileira de Zootecnia, v.36, n.5, p.1419-1425, 2007.

OLIVEIRA, L.B. Produção e valor nutritivo de diferentes forragens e de suas respectivas silagens. 2008. $46 \mathrm{f}$. Dissertação (Mestrado em Zootecnia) - Universidade Estadual do Sudoeste da Bahia, Vitória da Conquista, 2008.

PAULINO, M.F.; NASCIMENTO, M.L.; COUTO, V.R.M. et al. Uso da suplementação: como, quando e por quê? In: MUNIZ, E.N. (Ed.) Alternativas alimentares para ruminantes. 2.ed. 2008. p.81-123.

PEREIRA, G.R.P.; MORAES, S.A.; GUIMARÃES JR., R. et al. Uso de co-produtos da agroenergia na alimentação animal. In: MUNIZ, E.N. (Ed.) Alternativas alimentares para ruminantes. 2.ed. 2008a. p.139-171.
PEREIRA, E.S.; REGADAS FILHO, J.G.L.; ARRUDA, A.M.V. et al. Equações do NRC (2001) para predição do valor energético de co-produtos da agroindústria no nordeste brasileiro. Revista Brasileira de Saúde e Produção Animal, v.9, n.2, p.258269, 2008b.

PESSOA, R.A.; LEAO, M.I.; FERREIRA, M.A. et al. Palma forrageira, bagaço-de-cana e uréia associada a diferentes suplementos em dietas para novilhas da raça Girolando. In: REUNIÃO ANUAL DA SOCIEDADE BRASILEIRA DE ZOOTECNIA, 44., 2007, Jaboticabal. Anais... Jaboticabal: Sociedade Brasileira de Zootecnia, 2007. (CD-ROM).

SÁ, J.L.; SÁ, C. O Sistema Glória de produção de leite para o semi-árido. Petrolina: Embrapa - CPSATA, 2006. 4p. (Comunicação Técnica, 77).

SEREVINO, I.S. O que sabemos sobre a torta de mamona. 31p. Embrapa Algodão: 2005. (Documentos, 134).

SILVA, F. M. Substituição do farelo de soja pelo farelo de algodão corrigido com uréia em dietas à base de palma forrageira para vacas em lactação. 2008, 37f. Dissertação (Mestrado em Zootecnia) - Universidade Federal Rural de Pernambuco, Recife, 2008.

SILVA, J.G.M. Utilização de cactáceas nativas [(Cereus jamacaru DC. E Pilosocereus gounellei (A. Weber ex K. Schum) Bly. Ex Rowl.] associadas a silagem de sorgo na alimentação de bovinos no Seridó Norte-riograndense. 1998. 88f. Dissertação (Mestrado em Zootecnia) - Universidade Federal Rural de Pernambuco, Recife, 1998.

SILVA, R.R.; FERREIRA, M.A.; VÉRAS, A.S.C. et al. Palma forrageira (Opuntia ficus indica Mill) associada a diferentes volumosos em dietas para vacas da raça Holandesa em lactação Acta Scientiarum. Animal Sciences, v.29, n.3, p.317-324, 2007a.

SILVA, J.G.M; LIMA, J.F.C.; MACIEL, F.C et al. Utilização e manejo do xiquexique e mandacaru como reservas estratégicas de forragem. Natal: EMPARN, 2007b. 36p. (Documentos, 33).

VALADARES FILHO, S.C. et al. Tabelas brasileiras de composição de alimentos para bovinos. 2.ed. Viçosa, MG: UFV; DZO; DPI, 2006a. 329p.

VÉRAS, R.M.L.; FERREIRA, M.A.; ARAÚJO, C.V. et al. Farelo de Palma Forrageira (Opuntia ficus-indica Mill) em Substituição ao Milho. 1. Digestibilidade Aparente de Nutrientes. Revista Brasileira de Zootecnia, v.31, n.3, p.1302-1306, 2002.

VÉRAS, R.M.L.; FERREIRA, M.A.; ARAÚJO, C.V. et al. Substituição do milho por farelo de palma forrageira em dietas de ovinos em crescimento. Desempenho. Revista Brasileira de Zootecnia. v.34, n.1, p.249-256, 2005.

WANDERLEY, W.L.; FERREIRA, M.A.; ANDRADE D.K.B.x et al. Palma forrageira (Opuntia ficus indica Mill) em substituição à silagem de sorgo (Sorghum bicolor (L.) Moench) na alimentação de vacas leiteiras. Revista Brasileira de Zootecnia, v.31, n.1, p.273-281, 2002.

WANDERLEY, W.L. Silagens e fenos em associação à palma forrageira para vacas em lactação e ovinos. 2008. $65 \mathrm{f}$. Tese (Doutorado em Zootecnia) - Universidade Federal Rural de Pernambuco, Recife, 2008. 